\title{
Comment on Structure and Function of Chlorosomes in Green Sulfur Bacteria-Nature's Failure, Nature's Wisdom, or a Biotechnological Artifact?
}

\author{
A. V. Galkin \\ Institute of Gene Biology, Moscow, 119334 Russia \\ The Editor, Biophysics \\ E-mail: Editor-the1aO@yandex.ru \\ Received August 13, 2012
}

DOI: $10.1134 / \mathrm{S} 0006350912040227$

Synopsis - In the wake of the physically based critique by Borisov (this issue), I've also failed to find any direct proof that the giant chlorosomes, particularly those of green sulfur bacteria, actually transfer any appreciable part of energy absorbed by their bulk 'BChl's $c / d / e$ even to the supposedly adjacent baseplate $\mathrm{BChl} a$. On aggregate evidence (surveyed up to July 2012), such chlorosomes certainly cannot be "the most efficient" and can hardly be regarded as "lightharvesting antennae." My most skeptical idea is that giant chlorosomes are not normal cell entities but 'pigment tumors' arising from severe metabolic distortions when the culture conditions are selected so as to obtain larger objects (note that just a few years of such biotechnological 'intensive care' have raised the reported size of "superantennae" in Chlorobi by more than an order of magnitude!). However, just a layer of e.g. BChl $c$ on a protein-organized 'baseplate' (which may be the true external antenna), properly spaced above-and-between the CsmA-bound BChl $a$, can indeed be photosynthetically helpful. The weak side of Borisov's essay is his biological/evolutionary interpretation-Nature's "first, largely unsuccessful" compensatory invention; in fact, green sulfur bacteria are not older than purple bacteria and are no less successful ecologically, whereas the "regulatory mechanism" he considers would actually be suicidal. If 'megachlorosomes' are indeed found in nature, then (apart from the most trivial purpose of pigment storage) there is one thing they can really do well - they can dissipate the absorbed energy; hence may I speculate that these green sacs are built-in heaters, by virtue of which e.g. Chlorobium species live cozily in Antarctic marine sediments...

I am ready to spell out and substantiate these and other points, and invite everyone interested to share and discuss the pros and cons, relying on sound evidence instead of wishful thinking. 